\title{
PENGGUNAAN MEDIA AUDIO VISUAL DALAM PEMBELAJARAN MENYIMAK DONGENG DI ERA DIGITAL
}

\author{
Riga Zahara Nurani ${ }^{1}$, Fajar Nugraha ${ }^{2}$, Geri Syahril Sidik ${ }^{3}$ \\ Universitas Perjuangan Tasikmalaya
}

\begin{abstract}
Learning in the 21st century is inseparable from the influence of digital technology. Learning listening of fairy tale with conventional method (teachers read a fairy tale in front of the class) is no longer suitable to be applied for the students in this digital era, so that a new breakthrough in the use of learning media is needed. Learning listening of fairy tale by using an audio visual media can be one of alternatives used by teachers. Research used an audio visual media in learning listening of fairy tale was conducted in SDN 6 Singaparna. Research method used is descriptive qualitative method. The enthusiasm of students in learning listening of fairy tale by using audio visual media is better than learning listening of fairy tale read by the teacher. This is seen from the average score of listening ability of student's fairy tales. The average listening ability of student's fairy tale using audio visual media is 84,53, while the average listening ability of student's fairy tale before the research was 67,20. In addition to making the average listening ability of student's fairy tale increased was by the use of audio visual media that also made students more active in the learning process. This is seen when the teacher asked a few questions when the fairy tale has been played, most students responded well to the questions given by the teacher.
\end{abstract}

Keyword: listening, fairy tale, media

\begin{abstract}
Abstrak: Pembelajaran di abad ke-21 ini tidak terlepas dari pengaruh teknologi digital. Pembelajaran menyimak dongeng dengan cara konvensional (guru membacakan dongeng di depan kelas) dirasa sudah tidak cocok lagi diterapkan pada siswa di era digital ini, sehingga diperlukan adanya terobosan baru dalam penggunaan media pembelajaran. Pembelajaran menyimak dongeng dengan menggunakan media audio visual dapat menjadi salah satu alternatif yang bisa digunakan oleh guru. Penelitian tentang penggunaan media audio visual dalam pembelajaran menyimak dongeng dilakukan di SDN 6 Singaparna. Metode penelitian yang digunakan adalah metode deskriptif kualitatif. Antusiasme siswa dalam pembelajaran menyimak dongeng dengan menggunakan media audio visual lebih baik daripada pembelajaran menyimak dongeng yang dibacakan langsung oleh gurunya. Hal ini terlihat dari rata-rata kemampuan menyimak dongeng siswa. Rata-rata kemampuan menyimak dongeng siswa setelah menggunakan media audio visual adalah 84,53, sedangkan rata-rata kemampuan menyimak dongeng sebelumnya hanya 67,20 . Selain membuat rata-rata kemampuan menyimak dongeng siswa meningkat, penggunaan media audio visual juga membuat siswa lebih aktif dalam proses pembelajaran. Hal ini terlihat saat guru mengajukan beberapa pertanyaan saat dongeng telah diputar, sebagian besar siswa merespon dengan baik pertanyaan-pertanyaan yang diberikan oleh guru.
\end{abstract}

Kata Kunci: menyimak, dongeng, media

PENDAHULUAN

Menyimak merupakan salah satu aktivitas yang dilakukan oleh seseorang untuk mendapatkan informasi atau pengetahuan baru. Dengan menyimak, maka pengetahuan seseorang dapat

'Universitas Perjuangan Tasikmalaya, Email: rigazn回gmail.com

${ }^{2}$ Universitas Perjuangan Tasikmalaya, Email: fajarngrha国gmail.com

3 Universitas Perjuangan Tasikmalaya, Email: geri.syahril.unper 
bertambah. Hal ini karena tujuan utama dari menyimak adalah memperoleh informasi yang disampaikan oleh orang lain. Dalam menyimak, terdapat proses besar mendengarkan, mengenal, serta menginterpretasikan lambang-lambang lisan (Tarigan, 2008). Dengan demikian, semakin sering seseorang menyimak maka semakin banyak pula informasi atau pengetahuan yang ia peroleh.

Di sekolah dasar, pembelajaran menyimak sudah diberikan kepada siswa. Salah satunya adalah menyimak dongeng. Pembelajaran menyimak dongeng biasanya dilakukan dengan cara guru membacakan dongeng di depan kelas dan siswa duduk mendengarkan di meja masing-masing. Pembelajaran dengan cara seperti ini dirasa sudah tidak efektif lagi diterapkan pada siswa di era digital. Hal ini karena siswa sudah terbiasa mendapatkan informasi secara cepat dan akurat dengan bantuan teknologi. Oleh karena itu, diperlukan suatu inovasi dalam pembelajaran menyimak dongeng dewasa ini.

Penggunaan media audio visual dapat menjadi salah satu terobosan baru dalam pembelajaran menyimak dongeng. Bila biasanya guru yang membacakan dongeng untuk siswa, maka dengan menggunakan media audio visual siswa menyimak dongeng melalui video yang telah disiapkan oleh guru. Melalui media ini, siswa tidak hanya mendapatkan rangsangan lewat indra pendengaran saja, tetapi juga lewat indra penglihatan. Dengan demikian, proses pembelajaran menyimak dongeng dapat lebih bermakna dan kecil kemungkinan terjadinya kekeliruan dalam penyampaian isi dongeng.

Pada dasarnya, penggunakan media pembelajaran audio visual ini diharapkan dapat meningkatkan hasil belajar siswa, khususnya dalam pembelajaran menyimak dongeng. Siswa mampu memahami unsurunsur intrinsik dongeng dengan baik seperti tokoh, watak, latar, tema, alur, dan amanat. Selain itu, siswa juga diharapkan lebih aktif dalam proses pembelajaran. Hal ini sejalan dengan pendapat yang dikemukakan oleh
Jalongo dalam Bingol (2014, hlm. 2) "If we expect children to become good listeners, we will need to do more than worry, complain or demand. We need to teach them become active listeners". Jika kita mengharapkan siswa menjadi pendengar yang baik, maka kita harus mengajari mereka menjadi pendengar yang aktif.

Beberapa penelitian tentang penggunaan media dalam pembelajaran menyimak dongeng pernah dilakukan oleh peneliti lain. Salah satunya adalah penelitian yang dilakukan oleh Widyaningrum (2015), penggunaan media audio dalam keterampilan menyimak terbukti mampu meningkatkan kemampuan menyimak dongeng. Hal ini karena minat siswa untuk mengikuti pembelajaran menjadi lebih meningkat. Peningkatan tersebut terjadi dalam proses penentuan isi dongeng mengenai tokoh dan latar dongeng. Selain itu terjadi peningkatan pula pada aspek perhatian, keseriusan, dan keaktifan

\section{TINJAUAN PUSTAKA}

\section{Hakikat Menyimak}

Tompkins \& Hoskisson (1991) memaparkan bahwa menyimak merupakan sebuah proses menerima, memahami, dan menetapkan arti. Menyimak tidaklah sama dengan mendengarkan. Pada proses mendengarkan, seseorang menerima pesan yang diujarkan oleh pembicara namun bisa saja ia tidak memahami atau menangkap makna yang diujarkan. Dalam proses menyimak, ada usaha sadar yang dilakukan seseorang untuk memahami serta menginterpretasikan pesan yang diujarkan oleh pembicara.

Seseorang dalam menyimak suatu ujaran pastinya memiliki tujuan khusus. Adapun tujuan dari menyimak dipaparkan oleh Tompkins \& Hoskisson (1991) ke dalam lima macam, yaitu:

a. Discriminative listening

$\begin{array}{lrr}\text { Seseorang } r \quad \text { menyimak } & \text { untuk } \\ \text { membedakan suara } & \text { dan } \\ \text { mengembangkan } & \text { sensitifitas } \\ \text { komunikasi nonverbal. } & \end{array}$




\section{b. Comprehensive listening}

Seseorang menyimak untuk memahami pesan, dan ini merupakan tujuan yang paling wajib dalam beragam aktivitas menyimak.

c. Critical listening

Seseorang menyimak untuk memahami dan kemudian mengevaluasi pesan tersebut.

d. Appreciative listening

Seseorang menyimak orang yang berbicara atau yang membaca untuk menikmati.

e. Therapeutic listening

Seseorang menyimak orang yang berbicara untuk membicarakan sebuah masalah.

Dalam pembelajaran menyimak, terdapat unsur-unsur dasar yaitu pembicara, penyimak, bahan simakan, dan bahasa lisan yang digunakan (Cahyani \& Hodidjah, 2007). Pembicara ialah orang yang menyampaikan pesan atau informasi yang dibutuhkan oleh penyimak. Penyimak ialah orang yang mendapatkan pesan atau informasi dari seseorang. Bahan simakan ialah pesan yang disampaikan pembicara kepada penyimak. Bahasa lisan (primer) merupakan media yang dipakai dalam kegiatan menyimak.

\section{Hakikat Dongeng}

Dongeng merupakan suatu cerita fantasi yang kejadian-kejadiannya tidak benar terjadi (Widjojoko dan Hidayat, 2009, hlm. 33). Istilah dongeng dapat dipahami sebagai cerita rakyat yang bersifat universal yang dapat ditemukan di berbagai pelosok masyarakat dunia. Dongeng sebagai salah genre cerita anak tampaknya dapat dikategorikan sebagai salah satu cerita fantasi dan dilihat dari segi panjang cerita biasanya relatif pendek.

Dongeng memiliki jenis-jenis khusus antara satu dengan yang lainnya. Adapun jenis-jenis dongeng yaitu:

a. Fabel

Fabel merupakan cerita tentang kehidupan binatang/ tumbuh-tumbuhan, seringkali dihubungkan dengan kehidupan manusia, dan biasanya bersifat sindiran, atau kiasan.

b. Parabel

Parabel adalah dongeng khayal yang mengandung ajaran yang baik. Munculnya parabel ini dimungkinkan karena pada waktu itu masih sangat terbatas pendidikan formal, sehingga diperlukan suatu alat untuk mendidik masyarakatnya.

c. Sage

Sage merupakan dongeng/cerita khayal yang memasukkan peristiwa-peristiwa, tempat kejadian, dan tokoh-tokohnya merupakan tokoh sejarah.

d. Mite/mitos

Mite atau mitos adalah dongeng yang bercerita tentang dunia dewa-dewi dan berkaitan dengan kepercayaan masyarakat.

e. Legenda

Merupakan cerita khayal yang dihubung-hubungkan dengan gejala alam, serta kenyataan-keyataan alam yang ada di dalam kehidupan masyarakat.

Dalam sebuah dongeng, terdapat unsur-unsur yang membangun sebuah dongeng. Unsur-unsur intrinsik dongeng menurut Cahyani dan Rosmana (2006, hlm. 187-188) yaitu tema, alur/plot, tokoh, latar, sudut pandang, dan pesan. Tema merupakan pondasi atau inti dalam suatu cerita. Plot didefinisikan sebagai rangkaian peristiwa yang disusun secara logis dalam suatu cerita. Tokoh merupakan lakon atau pemeran dalam suatu dongeng. Latar adalah situasi tempat, ruang, dan waktu yang digunakan para tokoh dalam suatu cerita. Sudut pandang adalah model atau cara pengarang dalam bercerita. Pesan adalah nilai yang hendak disampaikan oleh pengarang kepada pembaca.

\section{Media Audio Visual}

Kata media berasal dari bahasa Latin dan merupakan bentuk jamak dari kata medium yang secara harfiah berarti perantara atau pengantar. Dalam konteks pembelajaran, Gagne dalam Susilana \& 
Riyana (2008) memaparkan bahwa media merupakan berbagai jenis komponen dalam lingkungan siswa yang dapat merangsang siswa untuk belajar. Sejalan dengan pendapat Gagne, Briggs dalam Susilana \& Riyana (2008) juga menerangkan bahwa media merupakan sebuah alat untuk memberikan perangsang bagi siswa supaya terjadi proses belajar. Dengan kata lain, media dapat diartikan sebagai sesuatu yang dapat menjembatani guru mengajar dan merangsang siswa untuk belajar.

Media pembelajaran dapat dikelompokan berdasarkan jenis dan cara penggunaannya. Bretz dalam Rohani (1997) mengelompokan media ke dalam tujuh kelas, yaitu:

a. Media audio - motion - visual

Media yang paling lengkap dalam arti penggunaan di kelas dalam segala kemampuan audio dan visual. Misalnya: televisi, film, video tape, dan film TV recording.

b. Media audio - still - visual

Media ini dapat menampilkan suara maupun gambar tanpa gerak. Misalnya: sound film strip, sound slide set, rekaman still TV.

c. Media audio - seminotion

Yaitu media yang berkemampuan untuk menampilkan suatu motion yang berupa titik-titik, tidak secara utuh. Misalnya: telewriting, dan recorder telewriting.

d. Media motion - visual

Mempunyai kemampuan seperti media kelas 1, kecuali suara (audio) yaitu berupa media silent film.

e. Media still - visual

Berkemampuan untuk menyampaikan informasi secara visual, tetapi tidak dapat menyajikan motion. Yang termasuk media ini ialah: halaman cetakan, film-strip, gambar.

f. Media audio

Yaitu media yang menggunakan suara semata-mata. Misalnya radio, telepon, audio tape recorder.

Video merupakan salah satu jenis media audio visual. Media audio visual adalah media yang mengandalkan indera pendengaran dan indera penglihatan. Media audio visual merupakan salah satu media yang dapat digunakan dalam pembelajaran menyimak. Media ini dapat menambah minat siswa dalam belajar karena siswa dapat menyimak sekaligus melihat gambar. Menurut Kamus Besar Bahasa Indonesia, video merupakan rekaman gambar hidup atau program televisi untuk ditayangkan lewat pesawat televisi, atau dengan kata lain video merupakan tayangan gambar bergerak yang disertai dengan suara.

\section{METODOLOGI PENELITIAN}

Penelitian ini bermaksud mendeskripsikan penggunaan media audio visual dalam pembelajaran menyimak dongeng. Oleh karena itu, peneliti menggunakan metode deskriptif kualitatif untuk mendapat gambaran secara jelas pelaksanaan pembelajaran yang dilakukan. Hal-hal yang dijadikan objek penelitian adalah pelaksanaan pembelajaran dan kemampuan menyimak siswa setelah menggunakan media audio visual. Adapun subjek yang dijadikan penelitian adalah kelas V SDN 6 Singaparna Kabupaten Tasikmalaya.

Untuk memperoleh data penelitian, peneliti menggunakan teknik tes, observasi lapangan, dan dokumentasi. Adapun instrumen yang digunakan adalah lembar tes dan lembar observasi. Data dianalisis selama penelitian dan setelah penelitian berlangsung.

\section{HASIL PENELITIAN DAN PEMBAHASAN \\ 1. Hasil Penelitian \\ a. Pelaksanaan Pembelajaran}

Pembelajaran dimulai dengan guru menyapa siswa dengan salam dan salah seorang siswa memimpin teman-temannya untuk berdoa. Guru menanyakan kabar siswa dan menanyakan siapa yang hari itu tidak hadir. Guru mengingatkan kembali siswa tentang pembelajaran dongeng yang dilaksanakan minggu sebelumnya. Guru bertanya jawab dengan siswa tentang 
dongeng apa yang telah siswa baca selama beberapa hari ke belakang.

Setelah bertanya jawab tentang dongeng-dongeng yang siswa ketahui, guru menyampaikan bahwa hari ini akan kembali belajar menyimak dongeng. Guru menyiapkan peralatan yang diperlukan untuk pembelajaran menyimak dongeng seperti proyektor, sound system, laptop, dan CD dongeng anak. Siswa terlihat sangat antusias membantu guru menyiapkan peralatan karena hari itu siswa akan menyimak dongeng melalui sebuah video.

Sebelum video diputar, guru bertanya pada siswa apakah sebelumnya ada yang pernah mendengar tentang dongeng "Kisah Kejujuran Gadis Pemerah Susu". Semua siswa menjawab belum pernah ada yang mengetahui dongeng tersebut. Kemudian guru mengondisikan siswa agar duduk secara rapi dan nyaman agar bisa menyimak isi dongeng dengan baik. Dongengpun diputarkan oleh guru dan siswa menyimak dengan seksama.

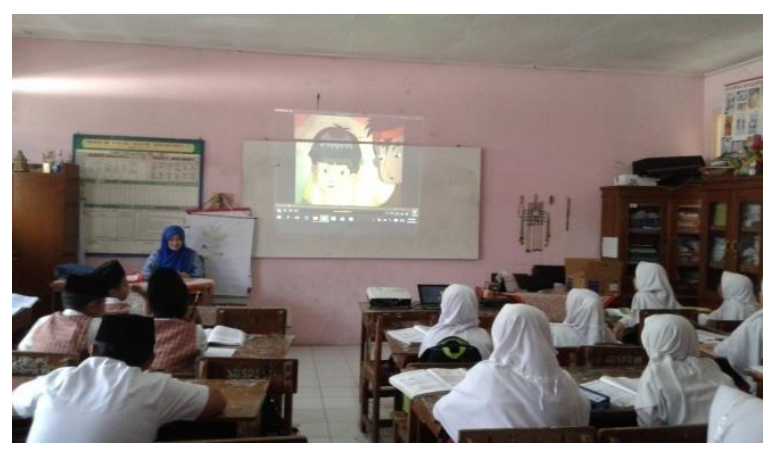

Gambar 1. Proses Pembelajaran Menyimak Dongeng

Dongeng berlangsung selama kurang lebih 15 menit. Setelah dongeng selesai diputar, guru bertanya pada siswa apakah siswa menyukai dongeng tersebut? Semua siswa terlihat antusias dan menyukai dongeng tersebut karena dikemas dengan cara yang menarik dan disampaikan dengan bahasa yang mudah dicerna. Guru bertanya jawab dengan siswa tentang unsur-unsur intrinsik dongeng tersebut. Siswa terlihat aktif dan merespon pertanyaan dari guru dengan baik.
Setelah bertanya jawab dengan siswa, guru mengeluarkan lembar tes yang berisi pertanyaan-pertanyaan tentang dongeng yang baru saja diputar. Soal dibagi menjadi 3 bagian, bagian ke-1 berisi 10 pertanyaan pilihan ganda, bagian ke-2 berisi 5 pertanyaan uraian singkat, dan bagian ke-3 berisi tentang perintah untuk siswa menceritakan kembali isi dongeng menggunakan bahasa sendiri.

\section{b. Kemampuan Menyimak Siswa}

Setelah seluruh siswa mengerjakan soal dan mengumpulkan lembar jawaban, guru mengoreksi hasil belajar siswa. Soal pada bagian ke-1 yang berisi 10 pertanyaan pilihan ganda memiliki bobot 1 . Soal pada bagian ke-2 tentang uraian singkat memiliki bobot maksimal 2 setiap soalnya. Sedangkan soal bagian ke-3 tentang kemampuan siswa menceritakan kembali dongeng dengan menggunakan bahasa sendiri memiliki bobot maksimal 5. Bobot maksimal keseluruhan soal yang diberikan oleh guru adalah 25. Berikut adalah hasil belajar siswa tentang kemampuan menyimak dongeng.

Tabel 1. Nilai Siswa

\begin{tabular}{|c|c|c|c|}
\hline Nama & Nilai & Nama & Nilai \\
\hline Siswa 1 & 84 & Siswa 16 & 84 \\
\hline Siswa 2 & 88 & Siswa 17 & 88 \\
\hline Siswa 3 & 92 & Siswa 18 & 92 \\
\hline Siswa 4 & 76 & Siswa 19 & 96 \\
\hline Siswa 5 & 76 & Siswa 20 & 76 \\
\hline Siswa 6 & 88 & Siswa 21 & 80 \\
\hline Siswa 7 & 84 & Siswa 22 & 80 \\
\hline Siswa 8 & 84 & Siswa 23 & 84 \\
\hline Siswa 9 & 76 & Siswa 24 & 88 \\
\hline Siswa 10 & 80 & Siswa 25 & 92 \\
\hline Siswa 11 & 92 & Siswa 26 & 80 \\
\hline Siswa 12 & 84 & Siswa 27 & 88 \\
\hline Siswa 13 & 76 & Siswa 28 & 92 \\
\hline Siswa 14 & 76 & Siswa 29 & 84 \\
\hline Siswa 15 & 84 & Siswa 30 & 92 \\
\hline \multicolumn{4}{|c|}{ TOTAL } \\
\hline \multicolumn{5}{|c|}{ RATA-RATA } & $\mathbf{2 5 3 6}$ \\
\hline
\end{tabular}

\section{Pembahasan}

\section{a. Pelaksanaan Pembelajaran}

Berdasarkan hasil penelitian yang telah dilakukan, pelaksanaan pembelajaran menyimak dongeng menggunakan media 
audio visual berjalan dengan lancar tanpa kendala yang berarti. Siswa terlihat antusias selama proses pembelajaran berlangsung. Penggunaan media audio visual cocok diterapkan pada siswa di era digital ini.

Tujuan menyimak yang diterapkan dalam pembelajaran ini adalah adalah comprehensive listening dan Appreciative listening. Siswa menyimak untuk memahami pesan yang disampaikan yaitu berupa unsur-unsur intrinsik berupa tokoh, watak, alur, latar, tema, dan amanat. Selain untuk memahami pesan yang disampaikan, tujuan dari menyimak ini adalah untuk menikmati dan mengapresiasi karya sastra. Bentuk dari mengapresiasi adalah dengan siswa mampu menceritakan kembali isi dongeng dengan menggunakan bahasa sendiri.

Jenis dongeng yang digunakan dalam penelitian ini adalah parabel. Dongeng ini mengisahkan kehidupan seseorang yang mengandung ajaran kebaikan. Jenis dongeng ini dipilih karena alur ceritanya lebih dekat dengan kehidupan siswa sehingga pembelajaran dapat lebih bermakna. Selain itu, dalam kisah ini juga mengajarkan nilai-nilai kebaikan yang dapat menjadi teladan untuk siswa. Dalam dongeng ini, siswa diajarkan untuk selalu hidup jujur meskipun orangorang di sekelilingnya berlaku tidak jujur. Meskipun orang di sekitar tidak tahu kalau dia berbohong, tetapi Allah maha tahu apa yang diperbuat oleh hamba-Nya.

Penggunaan media audio visual sebagai alat bantu dalam pembelajaran menyimak dongeng dirasa sangat efektif dan membuat pembelajaran lebih hidup. Hal ini terlihat dari minat siswa terhadap pembelajaran lebih baik dari pada biasanya. Siswa dapat menangkap pesan yang disampaikan dalam dongeng dengan baik. Ketika guru melakukan tanya jawab seputar isi dongeng, siswa mampu menjawabnya dengan tepat. Selain itu, siswa juga terlihat lebih menikmati pembelajaran menyimak dongeng daripada biasanya. Hal ini terlihat dari respon siswa setelah dongeng selesai diputar. Siswa mampu menceritakan kembali isi dongeng dengan baik, ini berarti siswa menikmati dan memahami dongeng yang telah diputar.

\section{b. Kemampuan Menyimak Siswa}

Berdasarkan rata-rata hasil menyimak siswa, kita dapat melihat bahwa terjadi peningkatan dalam kemampuan menyimak dongeng. Sebelum dilakukan penelitian ini, rata-rata kemampuan menyimak dongeng siswa adalah 67,20. Namun setelah dilakukan penelitian ini, kemampuan menyimak dongeng siswa meningkat menjadi 84,53. Perubahan kemampuan menyimak dongeng siswa terbilang cukup tinggi.

Bila dikaji lebih mendalam, perubahan kemampuan menyimak siswa mengalami peningkatan yang signifikan dalam pengerjaan soal bagian 2 dan bagian 3. Pada soal bagian 2, siswa diberi pertanyaan seputar isi dongeng namun dalam bentuk uraian singkat. Sebagian besar siswa mengalami peningkatan kemampuan saat ditanya tentang pendapat dan amanat yang terkandung dalam dongeng. Bila biasanya siswa kurang mampu mengeluarkan pendapat dirinya tentang dongeng yang disampaikan, kali ini siswa lebih mampu mengeluarkan pendapatnya. Selain itu, siswa juga lebih mampu menemukan amanat yang terkandung dalam dongeng tersebut. Hal ini dikarenakan siswa lebih memahami alur cerita dongeng dan kejadian apa saja yang terjadi dalam dongeng.

Pada soal bagian 3, hampir seluruh siswa mengalami peningkatan dalam nilainya. Pada bagian ini, siswa diminta untuk menceritakan kembali dongeng yang telah diputarkan dengan menggunakan bahasa sendiri. Bila biasanya siswa mendengarkan dongeng yang dibacakan oleh guru, kali ini dongeng tersebut disampaikan dengan menggunakan media pembelajaran yang lebih menarik. Karena itu, siswa lebih mampu memfokuskan diri dalam pembelajaran menyimak. Hal ini berdampak pada banyaknya informasi yang diperoleh siswa dalam proses menyimak 
tersebut. Sehingga, ketika siswa diminta untuk menceritakan kembali isi dongeng, siswa lebih mampu berekspresi.

\section{KESIMPULAN}

Kesimpulan dari penelitian ini adalah penggunaan media audio visual mampu meningkatkan kemampuan menyimak dongeng siswa di era digital. Siswa lebih antusias dalam pembelajaran menyimak dongeng karena disampaikan dengan menggunakan media pembelajaran yang menarik dan tidak menjenuhkan. Selain itu, aktivitas siswa di dalam kelaspun lebih baik daripada biasanya. Hal ini karena siswa diposisikan sebagai pendengar yang aktif dan cerita yang disampaikan dekat dengan kehidupan sehari-hari siswa.

\section{DAFTAR PUSTAKA}

Bingol, M.A dkk. (2014). Listening comprehension difficulties encountered by students in second language learning class. Journal of Educational And Instructional Studies In The World, 4 (4), hlm. 1-6.

Cahyani, I. \& Rosmana, I.A. (2006). Pendidikan bahasa Indonesia. Bandung: UPI Press.

Cahyani, I. \& Hodijah. (2007). Kemampuan berbahasa Indonesia di sekolah dasar. Bandung: UPI Press.

Rohani, A. (1997). Media instruksional edukatif. Jakarta: Rineka Cipta.

Susilana, R. \& Riyana, C. (2008). Media pembelajaran (hakikat, pengembangan, pemanfaatan, dan penilaian). Bandung: Jurusan Kurikulum dan Teknologi Pendidikan FIP - Universitas Pendidikan Indonesia.

Tarigan, H.G. (2008). Menyimak sebagai suatu keterampilan berbahasa. Bandung: Angkasa.

Tompkins, G. E. \& Hoskisson, K. (1991). Language arts: Content and teaching strategies. Order Processing, Merrill, an imprint of Prentice Hall, PO Box 11071, Des Moines, IA 50336-1071.
Widjojoko \& Hidayat, Endang. (2009). Teori \& sejarah sastra indonesia. Bandung: UPI PRESS.

Widyaningrum, H. K. (2016). Penggunaan Media Audio untuk Meningkatkan Kemampuan Menyimak Dongeng Anak PADA Siswa Kelas IV Sekolah Dasar. Premiere Educandum: Jurnal Pendidikan Dasar dan Pembelajaran, 5(02). 